\title{
Comunidades, patrimonio y arqueólogos: relaciones entre municipios e instituciones culturales de Oaxaca en el periodo indigenista*
}

\author{
Comunidades, patrimônio e arqueólogos: relações entre os municípios e \\ instituições culturais de Oaxaca no período indigenista \\ Communities, heritage and archaeologists: relationships between municipalities and \\ cultural institutions in Oaxaca in the indigenista period
}

Manuel Burón Díaz**

\begin{abstract}
Resumen: A raíz de procesos recientes de descentralización, empoderamiento y devolución patrimonial, así como con el surgimiento de museología comunitaria, se ha venido a celebrar la reciente participación de las comunidades indígenas latinoamericanas en los procesos de construcción y cuidado del patrimonio. Sin embargo, la historia de la relación entre comunidades indígenas e instituciones culturales por el manejo del patrimonio posee una larga tradición. El objetivo del presente artículo es analizar, a través de los informes de exploración de algunos de los más reconocibles especialistas del indigenismo mexicano, las relaciones que se fueron estableciendo a lo largo del siglo XX en el estado de Oaxaca entre las instituciones culturales y municipios por el cuidado del patrimonio.
\end{abstract}

Palabras clave: patrimonio; museos comunitarios; comunidades indígenas; indigenismo; Oaxaca, México.

Resumo: Partindo de processos recentes de descentralização, transferência de poderes e devolução patrimonial, assim como com o surgimento da museologia comunitária, tem-se vindo a celebrar a recente participação das comunidades indígenas latinoamericanas nos processos de constituição e preservação do patrimônio. Não obstante, a história da relação entre comunidades indígenas e instituições culturais na manipulação do patrimônio possui uma larga tradição. O objetivo do presente artigo é analisar, através dos relatórios de exploração de alguns dos mais reconhecidos especialistas do indigenismo mexicano, as relações que se foram estabelecendo ao longo do século XX no estado de Oaxaca entre as instituições culturais e os municípios em prol da preservação do patrimônio.

Palavras chave: patrimônio; museus comunitários; comunidades indígenas; indigenismo; Oaxaca, México.

\begin{abstract}
As a result of recent processes of decentralization, empowerment and heritage return, together with community museology, recently it has been praised the participation of Latin American indigenous communities in the heritage configuration and protection. However, the history of the relationship between indigenous communities and cultural institutions concerning heritage management comes from a long tradition. The aim of this article is to analyze, through exploration reports from some of the most renowned experts in Mexican indigenismo, the relationships that were established throughout 20th Century in the state of Oaxaca between cultural institutions and municipalities on heritage protection.
\end{abstract}

Keywords: Heritage; community museums; Indian communities; indigenism; Oaxaca, Mexico.

\footnotetext{
* El presente trabajo se inscribe en la participación y confluencia de dos proyectos de investigación. El primero lleva por título "Museos, memoria y antropología: América y otros espacios de investigación" (HAR2009-10107) financiado por el Ministerio de Ciencia e Innovación del Gobierno de España. El segundo es "Los reversos del indigenismo: socio-historia de las categorías étnico-raciales y sus usos en las sociedades latinoamericanas" (HAR201341596-P) financiado a su vez por el Ministerio de Economía y Competitividad del Gobierno de España.

** Doctor en Historia por el Instituto Universitario de Investigación Ortega y Gasset/Universidad Complutense de Madrid (IUIOG-UCM). dados biográficos_biographic data
} 
“... buscando la huella de su cuna, en la manifestación luminosa del pasado ancestral, que, como una sabiduría imborrable, dejó grabada la piedra no tocada por la mano de los siglos."

RAMÓN ROBLES, 1932

En octubre de 2008 un grupo de campesinos de la colonia Miguel Hidalgo en el estado mexicano de Chiapas, tomaron a la fuerza el yacimiento arqueológico maya de Chinkultic. Su objetivo era adquirir la gestión, en manos del Instituto Nacional de Antropología e Historia (INAH), en favor de su ejido. El operativo de desalojo por parte de las fuerzas del orden acabaría con el saldo de seis campesinos muertos ${ }^{1}$.

Diez años antes, al norte de Chiapas en el Estado de Oaxaca, un grupo de arqueólogos de la Universidad Nacional Autónoma de México (UNAM) encontraría una rica tumba en el término municipal de San Francisco Cajonos en la que, entre su ajuar, destacaba un pectoral de oro. Los arqueólogos abandonaron el lugar, hasta que un joven estudiante oriundo de dicho pueblo leería en la Gaceta de la UNAM la publicación de los resultados de la excavación. El estudiante se avino a comunicarlo a las autoridades de San Francisco que así tuvieron la primera noticia de su existencia (OLVERA TAPIA, 1999, p. 19) ${ }^{2}$. La población consideró que el grupo de arqueólogos había sustraído una pieza importante que en realidad pertenecía a la comunidad. Comenzó así un litigio para que el pectoral les fuera devuelto, cosa que finalmente y tras mucha insistencia consiguieron.

Valgan ambos ejemplos para constatar un hecho: las relaciones entre instituciones culturales, patrimonio y comunidades indígenas han cambiado radicalmente en las últimas décadas. A raíz de procesos tan globales como el alzamiento del multiculturalismo, el retroceso del estado o los procesos de descentralización, el anteriormente "inalienable patrimonio de la nación", en mayor o menor medida, ha sido cuestionado en favor

\footnotetext{
1 Un artículo previo a dicho enfrentamiento ya avisaba de la tensión que generaba la custodia del yacimiento entre la familia de los propietarios del terreno y la gente de la vecina colonial de Hidalgo, considerando estos últimos que "debería ser ella quien recibiera los beneficios económicos del turismo en Chinkultik y no el gobierno federal" (véase: MORALES CANO, 1999).

2 Dos años después, comenzado el litigio, el mismo equipo de arqueólogos vuelve a informar del análisis de los objetos en la Gaceta de la UNAM, pero ya se hace eco del proceso de devolución del pectoral, al afirmar que "la pieza del que parece ser del último gobernante de San Francisco Caxonos espera que los modernos descendientes de los antiguos zapotecas le erijan su nueva morada" (CARRILLO, 2001, p. 19).
}

de las diferentes culturas, regiones o grupos sociales que componen los estados. Corrientes asociadas a diferentes disciplinas (antropología crítica, arqueología post-procesual, o nueva museología) comenzaron a pugnar por un logro: el patrimonio debía, en cierta manera, volver del Estado a sus legítimos poseedores, no ya solo en su posesión material (cosa que raramente sucedió) o en la gestión y su aprovechamiento en cuanto que recurso económico para el presente, sino también en lo que respecta a la producción de significados respecto al mismo. De esta manera las comunidades indígenas, a través de innumerables procesos de empoderamiento, tras un largo proceso de enajenación, por fin habrían podido recobrar o reconectar con su patrimonio (ARIZPE, 2009; BONFIL BATALLA, 1993). En palabras del museólogo Luis Gerardo Morales Moreno, "vemos que, al final del siglo XX, la representación etnográfico-arqueológica puede retornar a sus legítimos poseedores" (MORALES MORENO, 1995, p. 34).

Inmerso en este proceso global partiremos de un fenómeno específico, una de las manifestaciones más originales e interesantes de este proceso: los museos comunitarios del estado mexicano de Oaxaca. En dicho territorio y a lo largo de los años ochenta surgieron diferentes "museos de comunidad", en donde asesorados por los especialistas del INAH, los diferentes pueblos gestionarían en exclusiva y a través de sus propias tradiciones organizativas el patrimonio de sus territorios ${ }^{3}$. La iniciativa de los museos comunitarios de Oaxaca partía de una línea muy clara: la confluencia entre la llegada de la Nueva Museología a América Latina y la antropología crítica mexicana. La primera marcada por la Mesa de Santiago de Chile de la UNESCO en $1972^{4}$; y la

\footnotetext{
3 Existe una amplia bibliografía al respecto de los museos comunitarios oaxaqueños. Desde el punto de vista institucional destacan los diferentes textos de sus principales impulsores: Cuauhtémoc Camarena y Teresa Morales del Centro INAHOaxaca (CAMARENA; MORALES, 2010). Análisis críticos al respecto han destacado diferentes aspectos en el mismo: desde la importancia de las instituciones y de la proyección de una muy determinada corriente antropológica en la conformación de los mismos, hasta la significativa similitud del contenido expositivo de los mismos con el discurso museístico tradicional mexicano (BURÓN, 2012 y 2017; COHEN, 1989; ERIKSON, 1996; MORALES MORENO, 1995).

${ }^{4}$ En América Latina la iniciativa francesa del ecomuseo se traducía en la realidad latinoamericana en un mayor cariz social del museo: "[el museo] ha de ser una institución al servicio de la comunidad" debiendo "contribuir a llevar a la acción a dichas comunidades". Véase el monográfico que se le dedicó a dicha Mesa Redonda en la revista Museum, v. XXV, n. 3, 1973.
} 
segunda por la administración de Guillermo Bonfil Batalla en el INAH, quien alentaría iniciativas entre las que se encuentran los más claros precedentes de museología comunitaria mexicana ("Programa de Museos Escolares" en 1972 o la "Casa del Museo" en 1973).

En confluencia con dicha línea y dentro del fenómeno específico de la museología comunitaria oaxaqueña destacaremos tres características. Primero, el patrimonio pasaba a adquirir una inusitada importancia dentro de la sempiterna "cuestión indígena". En este sentido y en el marco específico mexicano, en cierta manera se consideraba que el patrimonio prehispánico, antes emanación esencial de la nación mexicana, no era sino atributo esencial de los pueblos indígenas del presente, y como tal debía ser devuelto a sus legítimos herederos. Esa reconexión con su propia cultura, ese adquirir el "control cultural" del patrimonio, habría de ser decisivo en cuanto que medio de liberación indígena ${ }^{5}$. Segundo, uno de los objetivos máximos de la antropología crítica en general y de la museología comunitaria de Oaxaca en particular, sería el reiterado fomento de la autonomía o autodeterminación indígena. Los especialistas, desde la decisiva declaración de Barbados (la primera y la segunda) criticarían toda medida exógena, impuesta verticalmente hasta entonces, abogando por el desarrollo endógeno o etnodesarrollo, donde los museos comunitarios no serían sino uno de sus más característicos despliegues ${ }^{6}$. Este insistir desde el campo profesional de la antropología en la

\footnotetext{
5 La cuestión del patrimonio sería central en la crítica al indigenismo desde la antropología. Guillermo Bonfil Batalla, director del INAH en los años setenta, realizaría notables labores a favor del desarrollo de una museología comunitaria y la aplicación de su llamada "teoría del control cultural", un llamamiento de la antropología a que las comunidades controlaran sus procesos culturales sin intermedio de especialistas ni instituciones (BONFIL BATALLA, 1988). El patrimonio desde estas perspectivas era tan importante que su posesión o su significación podía ser el marcador capaz de definir lo indígena: "[Indígena sería aquel] que se considera a sí mismo heredero de un patrimonio cultural específico y asume el derecho exclusivo de tomar decisiones en relación con todos los componentes de ese acervo cultural (recursos naturales, formas de organización social, conocimientos, sistemas simbólicos, motivaciones, etc.)"(BONFIL BATALLA, 1987, p. 42).

6 "[P]or etnodesarrollo se entiende el ejercicio de la capacidad social de un pueblo para construir su futuro, aprovechando para ello las enseñanzas de su experiencia histórica y los recursos reales y potenciales de su cultura, de acuerdo con un proyecto que se defina según sus propios valores y aspiraciones" (BONFIL BATALLA, 1982 , p. 131-147). Dicha obra incluía una declaración elaborada entre "indios y otros expertos" en la que se afirmaba, entre otras cosas, la existencia de "una dimensión civilizatoria propia, como rostros únicos y específicos del patrimonio de la humanidad"; la tierra "como base de su existencia en los aspectos físico y espiritual en tanto que entidad autónoma", fundamento y razón "de su relación con el universo y el sustento de su cosmovisión";
}

más elevada autonomía de las comunidades indígenas, en ese evitar la promulgación de medidas exógenas o verticales como manera más eficaz de conservación cultural, derivaría tanto en una cierta invisibilización actual en el trabajo de los antropólogos -muy preclara en el fenómeno de los museos comunitarios ${ }^{7}$ - como un oscurecimiento del periodo anterior, un definirse frente a lo que aquí denominaremos genéricamente como indigenismo ${ }^{8}$.

Efectivamente, el despliegue del indianismo, la antropología crítica y la nueva museología, se realizó frente a un indigenismo clásico caracterizado por el centralismo, el autoritarismo y el discurso homogeneizador en la construcción patrimonial de México durante buena parte del siglo XX. Según tal visión, generada desde el propio INAH, uno de los vicios patrimoniales del indigenismo habría sido su centralismo, que habría "generado una concentración de los museos nacionales y de las colecciones en la capital de la República, en detrimento del desarrollo cultural regional" (INAH, 1986, p. 7). En definitiva, se consideraba que durante todo el proceso de construcción nacional y, muy especialmente durante el indigenismo, el patrimonio habría sido saqueado de las comunidades, el museo tradicional habría respondido así a "una historia de concentración de poder y riqueza, [que] en muchos casos reflejó la habilidad de los grupos dominantes para exhibir tesoros y trofeos arrebatados a otros pueblos" (CAMARENA; MORALES, 2010, p. 139 [la traducción es nuestra]).

y en tanto que poseedores de su territorio también se apela al derecho "al patrimonio natural y cultural que el territorio contiene y a determinar libremente su uso y su aprovechamiento" (BONFIL BATALLA, 1982, p. 24-25).

7 "El museo comunitario es creado por la misma comunidad: es un museo de la comunidad, no elaborado en su exterior para la comunidad", explica en el sitio web de la asociación. Añadirían sus principales impulsores desde el Centro INAH-Oaxaca, "El museo comunitario es un instrumento para desarrollar nuestro autoconocimiento (...) el museo comunitario no presenta la visión de agentes externos, es un instrumento para la autodeterminación" (CAMARENA; MORALES, 2015).

8 Existe cierta confusión acerca del término. Por indigenismo puede entenderse cualquier aproximación que tenga como principal objetivo y preocupación lo indígena, y puede producirse en cualquier época o contexto. Es el caso, por ejemplo, de la definición de Luis Villoro que entiende al indigenismo como un "conjunto de concepciones teóricas y de procesos concienciales que, a lo largo de las épocas, han manifestado lo indígena”, una definición útil para señalar la ubicuidad en la realidad virreinal y mexicana de una preocupación por lo indígena. Pero en este trabajo nos referiremos al indigenismo en tanto política cultural posrevolucionaria que en puridad comenzaría con el Primer Congreso Indigenista Interamericano, celebrado en Pátzcuaro, México en 1940 y concluiría con la Primera Declaración de Barbados en 1971 (VILLORO, 1987, p. 14). (Véase: GIRAUDO; MARTÍN-SÁNCHEZ, 2011). 
Sin embargo ¿cuánto hubo de verdad en este saqueo patrimonial a las comunidades? ¿cuál fue el verdadero papel de las instituciones culturales y las comunidades indígenas en el proceso de construcción de patrimonios nacionales y regionales? En el presente trabajo pretendemos arrojar una mirada histórica a las relaciones entre los grandes nombres del indigenismo y los municipios oaxaqueños en aquellos lugares en los que actualmente encontramos museos comunitarios ${ }^{9}$. Se pretende matizar así, en primer lugar, una visión en exceso teórica y celebratoria en el presente, pesimista respecto al pasado reciente, en la que por medio de dichos museos las comunidades, arrebatado durante largo tiempo su patrimonio, en la actualidad habrían reconectado con su cultura material. Con la premisa de que el patrimonio es un constructo -no se encuentra, ni es esencia de ningún pueblo o territorio- creemos fundamental la labor de los grandes especialistas del indigenismo mexicano en su articulación, pero también lanzamos la hipótesis de que, en esa construcción de patrimonios, lejos de estar simplemente excluidas, las comunidades fueron actores fundamentales. Y, más aún, en ese proceso de construcción el patrimonio pudo servir a los municipios como medio de negociación con las instituciones para adquirir cierto espacio político y visibilidad durante todo el siglo $\mathrm{XX}$, lo que derivaría directamente en el fenómeno de los museos comunitarios. En otras palabras, el museo comunitario indígena, uno de los principales logros de la museología latinoamericana, no sería una enmienda al indigenismo sino una consecuencia lógica de éste.

En este sentido, el objetivo de este artículo es volver la vista atrás para abocarnos a averiguar cómo fueron las relaciones entre instituciones, comunidades indígenas y patrimonio durante buena parte del siglo XX, particularmente en el estado de Oaxaca. En ello adelantamos-veremos como la labor de los indigenistas, lejos de simplemente coartar y suprimir las relaciones

\footnotetext{
9 Es ésta una muy habitual visión en los estudios de patrimonio $\mathrm{y}$ en los museum studies anglosajones que ha desencadenado una cierta reacción en la literatura sobre museos que se ha abocado a estudiar pasadas relaciones entre comunidades indígenas y patrimonio. Según esta reacción historiográfica, si bien a pesar de la situación de desventaja y en situaciones habituales de opresión, tales relaciones no serían una absoluta novedad, sino que las comunidades poseerían una larga tradición de relación con el patrimonio y con las instituciones culturales que lo gestionaban. Al respecto destaca la obra de Conal McCarthy para Nueva Zelanda quien prueba como los maoríes a pesar de estar inmersos en una situación de dominio -o precisamente por ello- participaron desde un principio en el proceso de patrimonialización y musealización de la cultura neozelandesa, utilizando su originalísimo patrimonio como herramienta de negociación política (MCCARTHY, 2007).
}

entre dichas comunidades y el patrimonio presente en su territorio, comenzaría una relación institucional que no tendría sino su lógica continuación en el fenómeno de la museología comunitaria. La incansable labor de grandes personajes como Alfonso Caso, Julio de la Fuente o muy especialmente, en cuanto a número y calidad de informes- Lorenzo Gamio, propició una relación entre comunidades indígenas e instituciones culturales por el cuidado y el conocimiento del patrimonio nacional. El INAH, institución con la hercúlea labor de catalogar, conservar y conocer el ingente patrimonio mexicano, necesitaba imperiosamente la colaboración de las comunidades ${ }^{10}$. Y en esa colaboración, los municipios ganaron una nada despreciable capacidad de acción en contacto con unas instituciones que los habían largamente ignorado $\mathrm{y}$, a la larga, el rédito de participar en los discursos regionalistas acerca del glorioso pasado prehispánico (y su sucesor, un presente de autenticidad indígena y artesanías) así como de gestionar y convertir en recurso el patrimonio presente en su territorio. Desde este punto de vista, en la labor de catalogación, sistematización y conservación del patrimonio nacional - esto es, en la construcción contemporánea del patrimonio mexicano- la labor de las comunidades indígenas -una vez más en nada ajenas a la vida nacional- habría sido fundamental.

\footnotetext{
${ }^{10}$ El INAH se sirvió desde principios de siglo de la colaboración de inspectores que, en cada estado del país, vigilaban y protegían el patrimonio arqueológico. Dicho periodo ha sido duramente criticado en las últimas décadas por la asociación a un nacionalismo y un uso patrimonialista del pasado. Al respecto afirma Luis Vázquez León: "Precisemos de paso que la férrea unidad de nacionalismo y ciencia fue establecida sin ambages por Gamio (1914), [por Manuel Gamio] siendo el tercer inspector de monumentos arqueológicos, a través de una metodología distintiva que conjuntó la investigación arqueológica a la administración monumental, anunciando lo que orgánicamente será el INAH desde 1939, institución que en definitiva reunirá ambas funciones, bajo un derrotero contrastante a lo que ocurre en otros países, en que ciencia y administración del pasado son independientes (...) Pensemos en la relación que guarda esta organización administrativa y la magnitud física de los bienes nacionales objeto del control centralizado. En 1912 la Inspección de Monumentos Arqueológicos -la primera institución formal de la arqueología gubernamental- solo administraba el museo de sitio y la zona arqueológica de Teotihuacán, la primera con ese estatus. Aparte del inspector general y su secretario, había dos subinspectores para vigilar todo el territorio de Chiapas y Yucatán, con la asistencia de 30 conserjes y 29 peones para trabajos de conservación. Cambiemos ahora de escenario. En 1962 el INAH disponía de dos departamentos (de un total de 17) para ocuparse de los monumentos arqueológicos: el Departamento de Monumentos Prehispánicos y el Departamento de Prehistoria; empero, ya sumaban 81 las zonas arqueológicas y estaban bajo exploración 12 más; disponía, para tal efecto, de 212 custodios y 200 técnicos, en su mayoría arqueólogos." (VÁZQUEZ LEÓN, 2003, p. 2015). Las relaciones entre coleccionistas, comunidades y arqueólogos también han sido estudiadas en otros marcos americanos, como
} por ejemplo en Perú, véase: (HERNÁNDEZ ASENSIO, 2012). 
Para nuestra argumentación nos serviremos de una fuente documental, utilizada habitualmente por la arqueología -no tanto por los estudios de patrimonioque puede ser de una enorme riqueza ya no sólo para el estudio de estos campos específicos sino también para el propio análisis del indigenismo mexicano. Nos referimos a los informes técnicos y de exploraciones, la mayoría de ellos todavía inéditos, que realizaron los diferentes especialistas y que se encuentran hoy día en el Archivo Técnico de la Coordinación Nacional de Arqueología del INAH.

En el centro de este conjunto de especialistas encontramos al equipo pionero en la arqueología indigenista y muy especialmente de Oaxaca. Un grupo de arqueólogos formado, entre otros, por Alfonso Caso, Ignacio Bernal, Lorenzo Gamio y Jorge de Acosta, así como de otros especialistas de relevancia como los antropólogos Julio de la Fuente -por aquella época realizando estudios en dicho Estado con Bronislaw Malinowski- a los que se unirían otros extranjeros como Frans Blom, Kent Flannery, Steve Kowalewski y un largo etcétera. Oaxaca a principios y mediados de siglo era un atrayente lugar para intelectuales de todo el mundo (interesados en admirar un mundo paralelo al oscuro panorama de la Europa de principios de siglo) $\mathrm{y}$, por ende, para la forja de un carácter tanto nacional como regional dentro de México, en el que el sustrato indígena era fundamental ${ }^{11}$.

Como es bien sabido, el nacionalismo revolucionario había creado en 1939 la principal institución cultural del país, el Instituto Nacional de Antropología e Historia, que adquiría una entidad jurídica propia a partir de su precedente, el Departamento de Monumentos Artísticos, Arqueológicos e Históricos. Un considerable incremento en su capacidad de recursos le permitiría abordar la ingente labor de "exploración, vigilancia, conservación, restauración, difusión de monumentos arqueológicos, históricos y artísticos de la República”. Se comenzaría a formar un personal altamente cualificado a través de la Escuela Nacional de Antropología (hoy ENAH, fundada en 1940) estableciéndose como una de sus principales funciones la de "obtener la colaboración de las autoridades estatales y municipales en la conservación y el estudio del patrimonio cultural", colaboración

\footnotetext{
${ }^{11}$ Principalmente de académicos y escritores, tanto mexicanos como extranjeros, llamados a forjar diferentes paradigmas. Durante la primera mitad del siglo XX, Oaxaca atrajo la atención de autores tan dispares como Franz Boas, Bronislaw Malinowski, José Vasconcelos, Alfonso Caso, Miguel Covarrubias, D. H. Lawrence, Aldous Huxley, Sergei Einsenstein, Malcolm Lowry, entre muchos otros (BOAS, 1912; MALINOWSKI; DE LA FUENTE, 1957; COVARRUBIAS, 1946).
}

que se materializó a través de diversos convenios con los gobiernos de los diferentes estados. En ello serían fundamentales la creación de instancias como la oficina de Dirección de Monumentos Prehispánicos y la Comisión Nacional de Monumentos, cuya misión fue custodiar, restaurar, registrar e investigar las numerosas zonas arqueológicas del país. Para la consecución de tales objetivos, entre todo el inmanejable patrimonio de la República Mexicana, se hubo de privilegiar ciertas zonas, precisamente aquellas que en principio representaban mejor la esencia de lo mexicano: la zona maya, la zona centro y Oaxaca (DEL RIO CAÑEDO, 2010, p. 27).

En esta última circunscripción el avance se vería espoleado por el descubrimiento, por parte de Alfonso Caso, de las ricas tumbas de Monte Albán; que volvían considerablemente más complejo el panorama cultural prehispánico mexicano, a la vez que parecía inaugurar la completa profesionalización de unas instituciones culturales que adquirían gran prestigio en el panorama internacional ${ }^{12}$. Pero aparte de estos resonantes descubrimientos, la labor de los especialistas del INAH estuvo volcada en la exploración y análisis de todo el acervo patrimonial que se escondía entre los cientos de pequeños municipios oaxaqueños. Los arqueólogos (y antropólogos) del INAH recorrieron enormes distancias en sus investigaciones, llamados por reportes de urgencia que aludían bien a descubrimientos bien a saqueos, estableciendo una red de yacimientos, roturando el campo patrimonial oaxaqueño y entablando una serie de relaciones con las comunidades que no carecería de duraderas consecuencias.

De ello dan prueba innumerables informes que tales especialistas enviaban a la dirección del INAH acerca de sus hallazgos, reflexiones, dificultades, costos y prioridades al respecto. En ellos se pueden analizar diferentes aspectos de interés como puedan ser: la progresiva construcción de un mapa patrimonial oaxaqueño más complejo (o, si se quiere, la 'construcción de otros patrimonios', como pueda ser el mixteco); muy especialmente la gran preocupación por la participación de comunidades e individuales en saqueos o comercio ilegal de materiales; la necesidad de control del territorio por parte del INAH, y por ello la necesidad de negociación y colaboración con individuales y comunidades a través del establecimiento de centros de resguardo, vigilantes o relaciones con

\footnotetext{
${ }^{12}$ De su importancia habla que Claude Lévi-Strauss situara instituciones como el Instituto Nacional de Antropología e Historia (INAH) o el Instituto Nacional Indigenista (INI) entre las instituciones antropológicas más importantes y capaces del globo (citado en: BROKMANN, 2013).
} 
coleccionistas o maestros en los propios pueblos; los diversos contextos de actuación frente al levantamiento de piezas y su resguardo en el museo regional: desde la negociación de los individuales para la cesión al INAH de las piezas en su posesión, hasta el nombramiento informal del propio municipio como custodia de los objetos encontrados; $y$, finalmente, el recelo de las comunidades y la especial necesidad de negociación y pacto por parte de las instituciones cuando de antiguos documentos territoriales se trata. Dentro de este catálogo de informes priorizaremos aquellos que se refieren a comunidades en las que actualmente existe un museo comunitario (generalmente adscrito a la Unión de Museos Comunitarios de Oaxaca), lo que nos permitirá observar la importancia que en el origen de estos centros tuvo la temprana relación entre las instituciones culturales y las propias comunidades.

En primer lugar, muchos de estos informes están imbuidos de la ideología y las concepciones de la época. Reflexivos textos, bellamente escritos, que permiten iluminar el periodo indigenista y su afán por desvelar una historia prehispánica capaz de igualar la nación mexicana a las grandes civilizaciones del mundo. El positivismo, el esplendor (pasado) de lo indígena, la ingente labor de rescate del pasado, ahora sólo recién comenzada, e incluso cierto poligenismo humanista, están presente en los mismos. En algunos de ellos somos capaces de apreciar intuiciones sobre nuevos estilos y culturas regionales que luego formarían todo un campo de la arqueología y generarían museos dedicados a ellos. Es el caso de la Mixteca Baja, los primeros reconocimientos apenas comenzarían a desvelar una cultura y un estilo escritural peculiar (posteriormente denominado como ñuiñe). Ramón Robles en 1932 sería el primero en acercarse a él calificando las estelas grabadas de la Mixteca Baja en cuanto que auténticos "códices de piedra". ${ }^{13}$

Resta conocer el secreto que pudo conservar a las comunidades indígenas dentro del bárbaro afán destructor de su tiempo, conquistador y belicoso. Esta clave nos la darán los túneles, sendas secretas del arrieral humano y que desconocemos en toda su magnitud, porque solo hemos recibido la noción de su existencia, a manera de cuentos envueltos en fantásticas relaciones de abuelito. Pero el cuento se va poco a poco haciendo historia (...) Esperamos que suene pronto el día de esta resurrección maravillosa,

${ }_{13}$ Para una continuación de los inicios de la arqueología en la Mixteca Baja (véase: GUZMÁN, 2007). con cuya etapa la humanidad llegará a demostrar que en todos los tiempos y todos los hombres llevan el gigantesco espíritu invisible que chisporrotea en el espacio, y que su cultura y civilización en todo tiempo han sido los medios de sintetizar las experiencias que la vida tributa. En todos los tiempos, las razas han sido despedazadas por el egoísmo. El hombre ha sido enemigo del hombre por el desenfreno de las pasiones. Las familias se han dividido infinitamente, hasta perder la noción de su origen, por la multiplicación biológica; pero espiritualmente van por la vida siguiendo una sola huella: la unificación por el Amor y la Fraternidad, buscando la huella de su cuna, en la manifestación luminosa del pasado ancestral, que como una sabiduría imborrable, dejó grabada la piedra no tocada por la mano de los siglos (ROBLES, 1932, p. 3).

Pero sería un error pensar que los especialistas se limitaron simplemente a seguir el discurso ideológico dominante de integración y construcción nacional. Con su trabajo los arqueólogos indigenistas comenzaron a matizar tanto un discurso nacional centrado obsesivamente en lo azteca (y en menor medida, lo maya) así como un discurso regional oaxaqueño centrado en lo zapoteco ${ }^{14}$. Es en este proceso donde destacó el progresivo desvelamiento de la importancia de la cultura mixteca $-\mathrm{y}$ en sentido estricto el comienzo de la construcción de un patrimonio mixteca- no sólo en la región del istmo sino en todo el altiplano mesoamericano. Una reivindicación que a la larga harían suya diversas comunidades indígenas, siendo la Mixteca, tanto la Alta como la Baja, una de las zonas donde más museos comunitarios han proliferado de todo Oaxaca. Las primeras impresiones a este respecto, en la justificación de las diferentes excavaciones en la zona, están recogidas en un informe de Ignacio Bernal en 1948.

\footnotetext{
${ }^{14}$ Especialmente reseñable fue la labor de Alfonso Caso. La publicación del artículo sobre las excavaciones en Monte Albán titulado "La tumba 7 de Monte Albán es mixteca" supuso el principio de la reivindicación de la cultura mixteca y un enfrentamiento con los discursos regionalistas tradicionales de Oaxaca. Éstos, al ensalzar la preeminencia azteca y zapoteca en la historia oaxaqueña, no podían aceptar que los lugares más representativos de las leyendas regionales, como Monte Albán o Zaachila, hubieran estado bajo control mixteca en los momentos previos a la conquista española. El hallazgo de piezas tan refinadas en la conocida Tumba 7 llevó a pensar a otros arqueólogos, como Ramón Mena, que todo había podido ser una pura invención de Caso. Muchos otros, como Zelia Nuttall, creyeron que esas piezas solo podrían haberse debido a aztecas o mayas. Los ataques a estas "hipótesis de las invasiones mixtecas en el Valle de Oaxaca", como las denomina Paddock, desatadas por el descubrimiento de Caso, han durado más de medio siglo (PADDOCK, 1986, p. 3-8).
} 
Es bien sabido que en el último siglo la importancia política estaba en manos de los aztecas y sus confederados, pero estamos mucho menos seguros de cuál sería el pueblo que hacía la aportación cultural de mayor importancia. Conforme vamos conociendo más la arqueología de México, vamos viendo que ninguno de los rasgos culturales cuyo conjunto forman la cultura azteca parece ser invento de este pueblo (...) Es en relación a este problema como resulta de gran interés el estudio de la arqueología mixteca (BERNAL, 1947, p. 54).

En el siguiente informe el propio Alfonso Caso da cuenta de sus numerosos viajes a la Mixteca, junto con Lorenzo Gamio, y el avance en las investigaciones en la localidad de Huamelulpan, en el distrito de Tlaxiaco, comunidad que hoy posee un gran museo comunitario en parte formado con los objetos obtenidos de las numerosas campañas allí efectuadas.

Tengo el honor de rendirle a usted [Eusebio Dávalos Hurtado, primer director del INAH] el informe que hicimos el señor Lorenzo Gamio y yo en Huamelulpan.

(...)

En mi primer viaje a la Mixteca en el año 1933, al pasar por Huamelulpan ya pude obtener fotografías de algunas piedras que existían y ahora están empotradas en la escuela o en la Iglesia (...) En 1959 don Lorenzo Gamio hizo otra expedición al mismo sitio y empezó a explorar la plataforma que está al poniente de la Iglesia (CASO, 1961, p. 6$)^{15}$.

En lo que respecta al aspecto práctico y procedimental lo que se desprende de los informes técnicos es una preocupación prioritaria por controlar el emergente e inmenso patrimonio de Oaxaca. Excavaciones particulares, malos usos y desconocimiento del patrimonio, compraventa, destrucción y saqueo de restos muebles e inmuebles, fueron algunos de las

\footnotetext{
${ }^{15}$ En dicho informe también incluye una digresión sobre el origen etimológico del lugar, que prueba hasta qué punto, en el INAH de la época, investigación y cuidado del patrimonio estaban entrelazados: "En mixteco el nombre de Huamelulpan es Yacundaba, que quiere decir cerro que voló, porque existe la leyenda de que este cerro, a cuyo pie se encuentra Huamelulpan, voló o se desprendió de otro que está cerca de Tlaxiaco, para evitar la huida de una princesa. En unos títulos de 1801 que vi, se llamaba Huanemilolpan, pero según yo es un error, pues en los títulos más antiguos se llama Huamelulpan" (CASO, 1961, p. 6).
}

actividades que reclamaron con urgencia la labor del personal del INAH, que desde un principio tendría como directiva el colaborar y concienciar a los municipios en el cuidado y vigilancia del patrimonio nacional. Un informe preliminar de 1949 recoge cual es el centro de las principales preocupaciones de los arqueólogos de Oaxaca y, a la vez, nos muestra la manera en que el incremento de la actividad relacionada con el estudio y el comercio de restos prehispánicos, había derivado en su contemplación en cuanto que importante recurso económico por parte de los habitantes de los diferentes municipios oaxaqueños.

Visitar (...) así como para evitar en lo posible los desenfrenados saqueos y destrucciones que últimamente se vienen haciendo a gran escala (...) A las destrucciones ya referidas, hay que agregar el desenfrenado comercio de objetos arqueológicos que se observa a cada paso y cada vez en mayor proporción. Se nos informa de algunos compradores que se dedican sin ningún escrúpulo y con todo el descaro al comercio de estos objetos y que constantemente hacen viajes de esta capital, y otros que van de Puerto de Veracruz a los lugares ya señalados y aún por otros muchos; es tal el afán de comprar ídolos, como ellos dicen, que hasta los choferes que van a las fábricas de ladrillos para transportar ese material hacen sus compras de idolillos y todo cuanto pueden en materia arqueológica. En algunos casos los señores compradores reparten sus tarjetas en las que anuncian que compran ídolos y pagan buenos precios.

(...)

Otro de los compradores y que quizás sea el más peligroso y que hace viajes frecuentes (...) es el señor Jorge Hanewaldt de nacionalidad alemana, pues hemos tenido noticias que hasta recomienda a los campesinos por los sitios que recorre que excaven lo más que puedan, que todo lo que encuentren le avisen telegráficamente (...)

Hasta hace pocos años la gente campesina no intentaba excavar para sacar idolillos, pero últimamente ya lo están haciendo (VALENZUELA; DEL PEÓN, 1949, p. 1 et seq.).

Lo que apunta dicho informe es a un cambio en la relación entre comunidades y patrimonio que parece previo, o por lo menos paralelo, a la catalogación y control de los restos patrimoniales de las comunidades por parte de las instituciones culturales 
mexicanas ${ }^{16}$. El aumento del comercio de antigüedades, ligado al crecimiento de turismo y artesanías, y a la demanda de autenticidad en objetos preshispánicos e indígenas, necesitaba de la colaboración activa de la población indígena y campesina, y espoleó enormemente la actividad de control patrimonial por parte del INAH. Ambos, saqueadores y arqueólogos, pugnaron por establecer relaciones de colaboración con los diferentes miembros de los municipios, estableciendo redes activas de control basadas en el patrimonio. Desde este punto de vista - contradiciendo en parte las acusaciones de la antropología crítica $\mathrm{y}$ las nuevas visiones sobre patrimonio- los especialistas del INAH buscaron principalmente la salvaguarda del patrimonio ante una posible destrucción, venta o descontextualización que muchas veces era llevada a cabo por extranjeros o por determinados miembros de las comunidades. Para el control del territorio y su patrimonio por parte de las instancias culturales se idearon diferentes estrategias: el nombramiento de inspectores o vigilantes en la comunidad, lo cual incluía también la existencia previa de interesantes personajes que ya se dedicaban a coleccionar tales objetos y a almacenarlos en algún lugar; la concienciación de las comunidades acerca de la importancia de la salvaguarda del patrimonio nacional mexicano, que pasaba por el reconocimiento y cuidado de las diferentes piezas y su no consideración en cuanto que recurso económico; la constante consulta y diálogo con determinados miembros de la comunidad para conseguir información acerca de posibles yacimientos, la cual resultaría especialmente problemática (como veremos) con aquellos objetos que sí eran considerados como auténtico y celoso patrimonio comunitario, significativo y en uso: aquellos lienzos y documentos

\footnotetext{
${ }^{16} \mathrm{La}$ valoración del patrimonio mexicano y la función del Estado como garante de su conservación es tan antigua (o más) que la propia Independencia, y especialmente contra la salida de estos objetos al extranjero, cuya preocupación no es, ni mucho menos, exclusiva del siglo XX. Así afirmaba García Icazbalceta: "Tampoco podemos quejarnos de la pobreza de nuestras colecciones, ni lamentar la pérdida de nuestras antigüedades, después de haber visto, hace poco, que el gobierno autorizó a un explorador extranjero para llevarse cuanto encontrara; y el contrario, aunque por fortuna desaprobado, fue defendido en el Congreso, por la razón de que para dar a conocer la historia de un país es indispensable que los objetos arqueológicos se exporten. Singular razón que obligaría a un cambio general de antigüedades entre todos los pueblos del globo. Díjose también que servían de ilustración al extranjero, y debíamos esperar que nos la devolviera en libros, de que sacaríamos más ventajas. ¡Adónde han ido a parar nuestros fieros y alardes de decoro nacional! Si los frailes acabaron con un tesoro, podrán quejarse, a lo sumo, los extranjeros, únicos capaces de aprovecharle, según se dijo en la representación nacional." (GARCÍA ICAZBALCETA, 1896, p. 72).
}

territoriales que poseían las autoridades municipales; la prohibición de realizar excavaciones particulares y la idoneidad de no mover o descontextualizar los diferentes hallazgos; el envío de diferentes piezas a los museos regionales para su conservación; $\mathrm{y}$, por último, el establecimiento -en aquellas comunidades que poseyeran un acervo significativo- de locales donde ir almacenando en las mejores condiciones los objetos patrimoniales encontrados.

En primer lugar, veremos cómo los arqueólogos buscaron en todo momento la figura de un intermediario comunitario con el que poder establecer una relación duradera de cara al control del patrimonio de las diferentes regiones y comunidades. De hecho, las visitas de urgencia de los especialistas estaban determinadas a que alguien de la comunidad informara a las instituciones de la aparición o destrucción de cualquier resto patrimonial. Podría ser un simple vecino -“[s]e efectuó dicha exploración gracias al informe de un vecino de la localidad [por Suchilquitongo] que tiene terrenos cercanos a la zona..." (GAMIO, 1946)-; o bien el Presidente Municipal -“[c]on el Presidente Municipal de ese lugar [por San Francisco Cajonos] me informé de donde habían sacado los objetos que se me indicaban en el oficio..." (GAMIO, 1945)-, según ambos testimonios de Lorenzo Gamio; lo cual bastaría por sí solo para ponernos sobre aviso sobre la colaboración comunitaria en el proceso de construcción y conservación patrimonial. $\mathrm{O}$, por último, quizás también se tratara de una figura comunitaria que se nos muestra especialmente interesante: coleccionistas individuales dentro de los propios municipios.

Un informe con fecha tan temprana como 1917 referido a la localidad de Teotitlán del Camino ofrece un valioso testimonio -en el que se da esa mezcla de consideraciones de tipo arqueológico y valoraciones de tipo antropológico después tan característica del indigenismo- en el que se prueba cómo la relación entre las comunidades y el patrimonio -al menos entre ciertos personajes de las mismas capaces de coleccionar y conservar objetos prehispánicos "con estimación"era previa a su institucionalización,

Teotitlán (lugar de dios) es una población de importancia al suroeste de la población y a cinco kilómetros de distancia, en la cima del cerro "San Bernardino" se encuentran las ruinas de un templo de la civilización mixteco-zapoteca, en la que se adoraba a un dios (...) Teotitlán en un tiempo fue el emporio del comercio entre la cabecera y Huautla, Huehuetla y Nanahuatipam (...) Su carácter poco 
común lo ha hecho distinguirse entre los otros pueblos (...) dando notables hijos, contándose inteligentes profesores, sabios doctores, prácticos abogados y patriotas ciudadanos (...) todavía existen algunos indígenas que no han podido abjurar de sus antiguas prácticas religiosas transmitidas de generación en generación (...) De regreso a la población tomé informes sobre las personas amantes de coleccionar objetos arqueológicos; obteniendo datos, me dirigí a los dominios de los señores Jesús Gomes y Emilio Alfaro, pudiendo convencerme de que efectivamente poseen y conservan con estimación, algunas joyas arqueológicas (VARGAS, 1917, p. 2, 8 et seq.).

Otro informe posterior de Lorenzo Gamio, respectivo al otro Teotitlán (Teotitlán del Valle, actualmente con un boyante museo comunitario) también nos habla sobre la importancia que en la labor arqueológica tuvieron los intermediarios. En este caso, más allá de la existencia previa de coleccionistas se alude a la figura de un vigilante, que estaría encargado de velar por el patrimonio evitando su saqueo, pérdida o comercio ${ }^{17}$. Es interesante también por la alusión a la construcción de la carretera panamericana (tan importante para el posterior despegue internacional de los textiles, el otro gran patrimonio de la zona) que mejoraría mucho la accesibilidad a las diferentes zonas del Estado. La afluencia de turismo y comercio incrementarían el número de descubrimientos y la necesidad del INAH de un progresivo mayor control sobre su patrimonio,

[Acudo a analizar] un pequeño montículo que fue destruido por los trabajadores de la carretera [internacional] Se desechó la idea de un saqueo reciente (...) La lápida de la entrada se encuentra ya en el Museo Regional de este Estado y los demás objetos en esta oficina a mi cargo a disposición de la superioridad. En vista de que en esa región no tenemos vigilante y el lugar donde apareció la tumba se encuentra bastante alejado de los centros de población, opté por volver a rellenar la tumba para evitar su destrucción (GAMIO, 1947).

\footnotetext{
${ }^{17}$ Existen multitud de testimonios en este sentido, por ejemplo: "En la actualidad el Departamento de Monumentos de la Secretaría de Educación Pública, teniendo en cuenta la importancia de la región [Los Tuxtlas, Veracruz], acordó nombrar un vigilante que radique en Catemaco y que se encargue del cuidado y vigilancia de la región, con el fin de evitar destrucciones y saqueos" (VALENZUELA, 1945, p. 101).
}

Entre aquellos personajes susceptibles de ser considerados como intermediarios, vigilantes o coleccionistas locales de patrimonio dentro de la comunidad, encontramos de nuevo a la importante figura del maestro. En ello es interesante el testimonio que aporta Julio de la Fuente para la región del Rio Cajonos, en el distrito de Villa Alta. Dicha zona, frontera entre el Valle Zapoteca y la Sierra Mixe, fue progresivamente explorada por diferentes especialistas (Julio de la Fuente en 1942, Lorenzo Gamio 1945 y otra vez en 1962 con el descubrimiento de la estela de Yagila ${ }^{18}$, hasta un reciente proyecto dirigido por Edith Ortiz Díaz en 1997). Dicha región, debido a su importancia, fue progresivamente considerada bastión patrimonial por el INAH, lo que precisamente generaría en época reciente múltiples museos comunitarios, desde el Museo Salesiano de San Pedro y San Pablo Ayutla Mixe, al Museo de Yagila, y el más reciente de la Unión de Museos Comunitarios de Oaxaca, el Museo de San Francisco Cajonos. A esta última localidad se refiere el informe de De la Fuente.

A un día y medio de camino aproximadamente de Teotitlán del Valle (...) El pueblo es histórico y Burgoa lo menciona como el lugar donde se encontraba el templo de los sacerdotes zapotecas más importantes de la región. Las grandes laderas del cerro se encuentran terraceadas, y en la parte superior se mira un pequeño mogote o amontonamiento de piedras, arqueológico, según los vecinos sobre el cual se colocó una cruz. Se recoge abundante tepalcatería de varios periodos en todas las terrazas (...) las laderas se cultivan intensamente, encontrando idolillos y vasijas los vecinos. No fue posible, sin embargo, conseguir algunas piezas y muchas de las sacadas han sido vendidas a turistas americanos (...).

\footnotetext{
${ }_{18}$ La estela de Yagila permanecería en la comunidad zapoteca de San Juan Yagila y se habilitaría un museo comunitario para ello. La conservación por parte de las comunidades, así como también sucede muchas veces con las instituciones, no garantiza las mejores condiciones para las piezas y necesita la implicación de gran parte de la comunidad. Así rezaba un reciente informe al respecto: "El estado del museo es bastante pobre, pues en el cuarto que se había asignado para esta función, se almacenan otros objetos como cajas, herramientas, disfraces, etc. También se han perdido las cédulas de registro de las piezas. La estela de Yagila reportado por Lorenzo Gamio hacia la década de los sesenta está en pésimas condiciones, pues, aunque está bajo techo, ha recibido agresiones por parte de los pobladores del lugar; los glifos de la parte posterior están prácticamente borrados y sobre este lado se pintó un letrero que dice: "di no a las drogas" (ORTIZ DÍAZ, 1998, p. 24 et seq.).
} 


\section{(...)}

En la escuela el profesor Aurelio López, nativo del lugar, reunió una pequeña colección de cabecitas y tepalcates, que aún conserva ahí (...).

(...)

Me permito hacer dos sugestiones respecto a estas piezas: que se recomiende a las autoridades locales la conservación de la colección que se encuentra en la escuela, sin perjuicio de que se haga la misma recomendación al actual maestro del lugar, el profesor Abelino León, persona muy competente, y que se pida a las mismas autoridades se traslade el ídolo y la pieza adicional [ídolo y pieza cónica] a la escuela, colocándosele en un buen sitio fuera del alcance de los alumnos, a fin de evitar que siga destruyéndose por acción de la intemperie y de los nativos, que algunas veces la han pintado con lápices y gises (DE LA FUENTE, 1942, p. 3).

En tal documento es posible apreciar el interés en habilitar un local, en este caso la escuela, para la protección de las piezas que se encuentren en aquellas comunidades anejas a importantes yacimientos arqueológicos. Es un caso parecido al de San Pedro y San Pablo Tequixtepec, la importancia arqueológica de dicha localidad, especialmente en la profusión de sus piedras grabadas, fue intuida por Lorenzo Gamio en uno de los pioneros reconocimientos de la Mixteca Baja. Dicho informe es interesante porque en él podemos apreciar el momento en que comenzaría a funcionar la idea de un museo en la comunidad, el municipio es responsabilizado de la custodia del patrimonio unos años antes de la promulgación de la Ley Federal sobre Monumentos de 1972 que habilitaría formalmente a ello.

Informado por las Autoridades del municipio de Chazumba, a través del Gobierno del Estado, en el sentido de que se había descubierto una gran oquedad en un montículo y se apreciaban restos arqueológicos, me trasladé inmediatamente a dicha población (...) Entrevisté a las autoridades y me informaron que unos individuos habían tratado de saquear dicho montículo, habiendo sido apresados y después dejados libres bajo fianza, como el delito era de orden Federal, turné las diligencias al Ministerio Público Federal en Oaxaca (...).

(...)

Los vecinos de un rancho cerca del cerro [Cerro de la Luna] me hablaron de otros lugares también con piedras lo que sería muy interesante visitar ya que son lugares donde aún no han entrado los saqueadores.

(...)

En un futuro viaje a ese lugar levantaré un plano exacto de la colocación de las Estelas y se tratará de recogerlas y concentrarlas en la Escuela o Municipio de Chazumba para después estudiarlas debidamente, por el momento responsabilicé a las autoridades para su custodia.

(...)

Ya de regreso aproveché visitar la población de Tequixtepec, donde había noticias desde hace tiempo de que ahí existían un gran número de estelas y efectivamente, las autoridades municipales han recuperado de un cerro contiguo alrededor de 20 monolitos y los concentrado en la plaza y edificio municipal, todas son muy interesantes; desde luego hablé con el Presidente del lugar indicándole que ya que habían bajado las estelas y que en principio era un error ellos eran los depositarios y responsables ante el Patrimonio Nacional de estas estelas, pues ya habiendo sido fotografiadas quedaban inventariadas, les aclaré que el error cometido con las estelas era quitarlas de su sitio sin marcar en un plano su posición, distancia y descripción del lugar (GAMIO, 1969).

Llegamos ahora a una de las cuestiones más polémicas acerca de las políticas patrimoniales del INAH en el periodo estudiado. Esto es, las habituales acusaciones acerca del saqueo que el INAH infringiría a las diferentes comunidades, especialmente las indígenas, auténticas poseedoras legítimas del patrimonio prehispánico, tanto cultural como territorialmente. Epítome, a su vez, de las malas praxis de autoritarismo y centralismo que desembocarían directamente en un paradigma democratizador de la ciencia, si se quiere, a través de sus diferentes despliegues: antropología crítica, arqueología postprocesual o, finalmente, museología comunitaria. En los diversos informes aquí analizados es difícil apreciar un proceso de saqueo o usurpación de patrimonio, ya no sólo porque sería un anacronismo considerar de tal modo la catalogación y conservación de bienes (que seguían siendo considerados propiedad inalienable de la nación y no de sus diferentes pueblos o comunidades), sino sobre todo porque estaban redactados por los mismos especialistas que posteriormente serían acusados de estar coaligados con un discurso hegemónico. Sea como fuere, el 
INAH desplegó diferentes estrategias a la hora de adquirir o no los diferentes objetos significativos de los cuales daban cuenta sus informes. En la inmensa mayoría de los casos podemos observar como los especialistas del INAH actuaron para proteger y evitar la alarmante destrucción del patrimonio de Oaxaca. Es cierto, como opinan recientes obras, que la suposición de que una sola institución, por muy mastodóntica que fuera, pudiera aprehender y proteger mínimamente dicho patrimonio era sumamente ingenua; pero habría que preguntarse, sobre todo a raíz de la febril actividad que se desprende de los presentes informes, qué habría sido del patrimonio oaxaqueño sin su incansable labor. Entre las diversas estrategias que se desplegaron, hemos visto numerosos ejemplos en que se procura que sea la propia comunidad la que obtenga la custodia, a través del nombramiento de dicha responsabilidad a las diferentes autoridades 0 intermediarios, para que conserven lo ya encontrado. Sin embargo, otras veces se consideraba que era mejor adquirir ciertos objetos de la propiedad de individuales y mandarlos estudiar y conservar en el Museo Regional. Para ello, de nuevo, era fundamental la intermediación y negociación entre instituciones, autoridades comunitarias e individuales. Como afirma Lorenzo Gamio: "De San Francisco Cajonos recogí un idolillo de jade color verde claro que estaba en poder de un particular, con la ayuda de las autoridades lo convencí que lo entregara para el Museo, siendo esos objetos los únicos que se pudieron obtener" (GAMIO, 1945, p. 4).

Pero había ocasiones $-\mathrm{y}$ esto es sumamente interesante- en que la comunidad se mostraba especialmente celosa de los objetos requeridos por los especialistas. Se trata de aquellos documentos territoriales (lienzos o títulos primordiales) utilizados y guardados por la comunidad para probar su adscripción histórica y legal al territorio. Para ello reproducimos extensamente el informe de Frans Blom en que se narra con toda literatura el hallazgo del Lienzo de Analco, importante documento territorial del siglo XVI identificado como de tradición tlaxcalteca ${ }^{19}$. En él se

\footnotetext{
${ }^{19}$ Frans Blom (1893-1963) fue un arqueólogo danés que muy pronto recalaría en México donde se volvió un muy relevante mayólogo y un defensor de la etnia lacandona. Se ganó la confianza de Manuel Gamio y, si atendemos al obituario de J. Eric Thompson, por la fecha de dicho informe Blom estaría saliendo de una profunda crisis personal y profesional suponiendo su vuelta al trabajo de campo. "Sus esperanzas de retornar al campo se alejaron, y estar sentado en una silla frente a un escritorio era para Frans un pobre sustituto de estar montado en una mula. Se refugió en la bebida descuidando seriamente su Departamento, y esto lo
}

muestra muy claramente el dilema que viene dado entre el estudio científico y la posesión comunitaria de un objeto significativo, sorprende por explícita la defensa de que dicho objeto permanezca en la comunidad (“debemos dejar a los analcos con su tesoro" ${ }^{20}$ ).

El que ha tenido la suerte de subir el camino áspero y sinuoso que conduce a Villa Alta desde Yalalag nunca se olvida de la belleza del paisaje. Dando vuelta a un cerro se abre un valle angosto y muy abajo se ven los pueblos de Villa Alta y Ladivioag casi escondidos en huertas tropicales y plantaciones de café. Un pastor guardando sus ovejas estaba tocando su chirimía y unas mujeres recogieron unas orquídeas para el altar de un santo. En una barranca honda corre un río caudaloso y en la distancia se ve el pueblo de Temaxcalápan situado en una falda de un cerro alto que está coronado con unas ruinas de un pueblo pre-cortesiano. Más lejos todavía relucen las paredes blancas de la pequeña iglesia del gracioso pueblo de Yatzona (...) Se nos habla de un documento antiguo (...) Existe la tradición que la gente de Analco son de origen Tlaxcalteca y que vinieron con los españoles en la conquista de la tierra de los mixes.

\section{(...)}

He sabido desde hace muchos años que todavía se guardan en lugares remotos e indígenas, documentos, códices o lienzos de la antigüedad. Siempre me han dicho que los dueños nunca enseñan sus tesoros a nadie y siempre he soñado con ver un tal tesoro ¿Me sonreía la suerte esta vez? ¿Iba a ver yo un documento antiguo? Así pensaba. Entramos en la casa que antes había sido ayuntamiento (...)

\footnotetext{
llevó a su renuncia como director en 1941. Ralph Roys y yo lo visitamos juntos en enero de 1942 a nuestro paso por Guatemala. Había perdido sus muebles y su biblioteca que tanto apreciaba. Su una vez acogedor departamento en Jackson Square, escenario de tantas grandes reuniones en el pasado, estaba completamente vació con excepción de algún colchón en el suelo. Esto nos produjo una gran tristeza. Frans estaba terminado y no parecía que podría recobrarse. Pero lo hizo" (THOMPSON, 1963, p. 310).

${ }^{20}$ La historia del lienzo explicita las tensiones que provocarían objetos tan significativos entre el recelo de las comunidades a compartirlos; el interés de las instituciones en estudiarlos y conservarlos; y el afán de los coleccionistas privados en adquirirlos. Muy poco después del descubrimiento del lienzo y de la decisión de Blom de dejarlo en la comunidad, dicho documento fue usurpado a la comunidad por un coleccionista privado. Frans Blom tuvo conocimiento de este hecho y denunció su desaparición del pueblo. El coleccionista privado fue apresado en la frontera al intentar sacarlo al extranjero. El Lienzo de Analco actualmente se encuentra en la colección de códices del Museo Nacional de Antropología (ASSELBERGS, 2007, p. 96).
} 
Algunos hombres (...) me miraban con sospecha. Durante siglos habían guardado sus documentos celosamente y pocos eran los de fuera que los habían visto. (...)

(...)

El lienzo de Analco contiene una riqueza de pormenores y detalles íntimos de la vida del pueblo y de los horrores de la conquista que se efectuó con una fiereza hitleriana (...) Nunca había visto un documento tan expresivo como el lienzo de Analco.

(...)

Como he dicho anteriormente solo tenía unas pocas horas a mi disposición para ver el lienzo de Analco, pero vi suficiente para afirmar que este documento histórico es interesantísimo y de sumo valor histórico. Debemos dejar a los analcos con su tesoro, pero al mismo tiempo es nuestro deber fotografiar y estudiar esta página grande de la historia mexicana que nos habla de viva voz a través de cuatro siglos" (BLOOM, 1945).

\section{Conclusión}

Hemos presentado en este apartado una serie de fuentes que demuestran la importante labor patrimonial de los arqueólogos y antropólogos del INAH en Oaxaca durante buena parte del siglo XX. Nos hemos centrado principalmente en aquellos aspectos procedimentales que puedan iluminar el establecimiento de relaciones entre comunidades y especialistas. En muchos de los casos hemos podido apreciar la inauguración de tales relaciones, y el establecimiento de conversaciones entre vecinos, coleccionistas, o autoridades de los municipios y los arqueólogos del INAH. Muchas de tales relaciones vinieron dadas por el conflicto (principalmente saqueos o venta de objetos) pero muchas otras también se basaron en la colaboración, a través del aviso acerca de, la capacitación, donación o incluso la temprana custodia de parte importante del patrimonio arqueológico o histórico de la región.

Toda esta labor vendría a materializarse con la llegada a la dirección del INAH Guillermo Bonfil Batalla, el comienzo de la crítica al indigenismo clásico y la promulgación de la Ley Federal sobre Monumentos y Zonas Arqueológicas, Artísticas e Históricas del 6 de mayo de 1972. Tal legislación habilitó la participación legal de "asociaciones civiles, juntas vecinales, y uniones de campesinos como órganos auxiliares para impedir el saqueo arqueológico y preservar el patrimonio cultural de la Nación" ${ }^{21}$. Los municipios oaxaqueños podían desde entonces implicarse por ley en el manejo de colecciones o bienes patrimoniales asumiendo el rol de "custodias" (pero, en su condición de bienes inalienables de la nación mexicana, no la propiedad) lo que desembocaría directamente en los diferentes programas de museos comunitarios. Sin embargo, en las páginas precedentes hemos podido apreciar cómo esa función venía gestándose, incluso realizándose explícitamente, desde la implementación de los trabajos de reconocimiento y catalogación propia de la primera mitad del siglo XX.

Por otro lado, la profusión sin precedentes en dicho periodo de estudios científicos, catalogaciones y descubrimientos por parte de estos científicos provocó una progresiva valoración del patrimonio -en sentido estricto, construcción del patrimonio- tanto internacional, como regional y comunitariamente. Muchas comunidades, algunas de las cuales participaron activamente, mano a mano, con los arqueólogos en las diferentes campañas arqueológicas, tomaron conciencia de la antigüedad e importancia cultural de su territorio, convirtiendo a su vez ese constructo patrimonial en un recurso simbólico o económico para el presente a través de plataformas tales como los museos comunitarios (bien atrayendo turismo, asociándolo a la producción de artesanías o utilizándolo para legitimar la adscripción inmemorial al territorio en conflictos de tierras, por poner los más repetidos ejemplos).

En definitiva, en los informes aquí aportados hemos podido apreciar cómo en muchas de aquellas comunidades que hoy poseen un museo comunitario, adscrito o no a la Unión de Museos Comunitarios de Oaxaca y al Centro INAH-Oaxaca (Teotitlán del Valle, Huamelulpan, San Francisco Cajonos, San Pedro y San Pablo Tequixtepec, Suchilquitongo, etc.) existe una larga tradición de contacto y colaboración entre municipio y especialistas. En aquellas regiones que fueron priorizadas en la época del indigenismo clásico -entre otras Mixteca Alta y Baja, Valles Centrales, Zona de Cajonos (no así otras como Papaloapan, por ejemplo)- fue precisamente donde en años recientes han surgido, asociados a tal tradición pero definiéndose frente a ella, los

\footnotetext{
${ }^{21}$ Ley Federal sobre Monumentos y Zonas Arqueológicas, Artísticas e Históricas, Capítulo 1, Artículo 2, del 6 mayo de 1972.
} 
principales procesos de empoderamiento patrimonial indígena ${ }^{22}$.

Además de la posible consideración de los museos comunitarios en cuanto que bastiones prestos a resistirse frente a la imposición y el saqueo de su patrimonio comunitario por parte del estado y las instituciones indigenistas -tal como opina parte de la literatura sobre dicho campo ${ }^{23}$, o como grupos subalternos recobrando un patrimonio enajenado durante siglos, el museo comunitario, decimos, podría ser de igual manera contemplado en cuanto que agente patrimonial del estado y las instituciones en el cuidado de la cultura material de la nación, como una derivación de los vigilantes e intermediarios que demandaban los indigenistas de principios de siglo, como una necesidad del INAH de abrirse a otros actores sociales ante la imposibilidad de manejar por sí solo el ingente patrimonio mexicano. Sin embargo, ello no sería otra cosa que una reedición del eterno debate sobre la concepción historiográfica de las comunidades indígenas; o bien consideradas en cuanto que bastiones de tradiciones, encerrados sobre sí mismos, ajenos y contrarios al estado y la vida nacional, o bien como agentes fundamentales del estado, cooptados y sumisos, atrapados por tanto en el eje de coordenadas que formarían contrarios irreconciliables como inmutabilidad y adaptación, resistencia o colaboración (GUARDINO, 2007, p. 232). Por ello, creemos más fructífera la consideración del papel de las comunidades y municipios en cuanto que actores políticos, que habrían desplegado diferentes respuestas hacia el patrimonio, ya sea individual o comunitariamente, de resistencia, indiferencia, lucro o colaboración, pero entre las que destacamos el continuo pacto o negociación con las instituciones centrales, una de las características históricas que han definido al municipio oaxaqueño. Unas comunidades, en definitiva, en nada ajenas al proceso de construcción del patrimonio mexicano.

${ }^{22}$ El estado de Oaxaca como zona privilegiada de actividades del INAH durante toda la época aludida podría ser añadido a las causas que intentan desentrañar el porqué del liderazgo actual de la antigua Antequera en las prácticas de museología comunitaria, entre las que suele dominar la de una mayor etnicidad y consecuente presencia de formas tradicionales de organización interna (FRAUSTO, 2015).

${ }^{23}$ Las visiones al respecto suelen incidir en un constante antagonismo y dicotomía entre especialistas e indígenas, centrando su crítica en el monopolio científico y patrimonial de las instituciones centrales, a que "los arqueólogos, historiadores y los llamados especialistas definan solos lo que requiere conservar y proteger de nuestro patrimonio cultural", como afirma Florescano. O bien reivindicando, tal como hace Vázquez León, "una nueva actitud abierta de los arqueólogos para negociar su objeto de estudio con otros actores sociales" (FLORESCANO, 1992, p. 2; VÁZQUEZ LEÓN, 2003, p. 99).

\section{Referências}

ARIZPE, Lourdes. El patrimonio cultural inmaterial de México. Ritos y festividades. México: Porrúa, 2009.

ASSELBERGS, Florine. The Conquest in Images: Stories of Tlaxcalteca and Quauhquecholteca Conquistadors. In: MATTHEW, Laura E.; OUDIJK, Michel R. (Ed.). Indian Conquistadors. Norman: University of Oklahoma Press, 2007.

BOAS, Franz. Notes on Mexican Folk-lore. In: Journal of American Folk-lore, v. 25, n. 97, p. 204-206, 1912. https://doi. org/10.2307/534821

BONFIL BATALLA, Guillermo. El etnodesarrollo: sus premisas jurídicas, políticas y de organización. In: VVAA, América Latina: etnodesarrollo y etnocidio. San José: FLACSO, 1982. p. 131-147.

. La teoría del control cultural. In: Anuario antropológico. Universidade de Brasilia, 1988. p. 13-53.

México profundo. Una civilización negada. México: CONACULTA, 1987.

. Nuestro patrimonio cultural: un laberinto de significados. In: FLORESCANO, Enrique (Comp.). El patrimonio cultural de México. México: FCE/CONACULTA, 1993. p. 28-56.

BROKMANN, Carlos. Alfonso Caso, el Indigenismo y la política cultural. In: BARNEY, Óscar et al. Los abogados y la formación del estado mexicano. Instituto de Investigaciones Jurídicas, México, 2013. p. 645-674.

BURÓN, Manuel. Los museos comunitarios mexicanos en el proceso de renovación museológica. In: Revista de Indias, v. LXII, n. 254, p. 177-212, 2012.

. El patrimonio recobrado: museos indígenas en México y Nueva Zelanda. 2016. Tesis (Doctorado) - Instituto Universitario Ortega y Gasset-Universidad Complutense de Madrid, Madrid, 2017.

CAMARENA, Cuauhtémoc; MORALES, Teresa. The community museum: a space for the exercise of communal power. In: Sociomuseology, v. 38, n. IV, p. 135-152, 2010.

Museos comunitarios: principios y prácticas actuales en México y América Latina. In: Seminario Permanente de Museología de América Latina, México, 21 de octubre de 2015, registro y transcripción de Manuel Burón. (mímeo).

CARRILLO, Sergio. Tenían los zapotecas amplio conocimiento de la metalurgia. Gaceta UNAM, México, 15 jan. 2001, p. 19.

COHEN, Jeffrey. Museo Shan-Dany: Packaging the Past to Promote the Future. In: Folklore Fórum, v. 12, n. 22, p. 16-36, 1989.

COVARRUBIAS, Miguel, Mexico South. The Isthmus of Tehuantepec. Alfred A. Knopf: Nueva York, 1946.

DEL RIO CAÑEDO, Lorenza. Las vitrinas de la nación. Los museos del Instituto Nacional de Antropología e Historia. México: INAH, 2010

ERIKSON, Patricia P. 'So My Children Can Stay in the Pueblo': Indigenous Community Museums and Self-determination in Oaxaca, Mexico. In: Museum Anthropology, v. 20, n. 1, p. 37-46, 1996. https://doi.org/10.1525/mua.1996.20.1.37

FLORESCANO, Enrique. El patrimonio cultural, entre los desafíos y el atraso institucional. In: Este Pais, n. 32, 1992.

FRAUSTO, Fátima, Alcances y limitaciones de los museos comunitarios en el Estado de Zacatecas, 2015. Tesis (Maestría) - Escuela de Conservación, Restauración y Museología - INAH, México, 2016. 
GARCÍA ICAZBALCETA, J. Obras de D. J. García Icazbalceta. México: Imp. De V. Agüeros, 1896. Tomo II, v. 2.

GIRAUDO, Laura; MARTÍN-SÁNCHEZ, Juan. (Ed.). La ambivalente historia del Indigenismo. Campo interamericano y trayectorias nacionales, 1940-1970. Lima: Instituto de Estudios Peruanos, 2011.

GUARDINO, Peter. El nombre conocido de la República. Municipios de Oaxaca, de Cádiz a la primera República Federal. In: ORTIZ ESCAMILLA, Juan; SERRANO ORTEGA, José Antonio (Ed.). Ayuntamientos y liberalismo gaditano en México. El Colegio de Michoacán-Universidad Veracruzana, México, 2000. p. 213-234.

GUZMÁN, Ángel Iván Rivera. Lorenzo Gamio y los inicios de la arqueología en la Mixteca Baja. Comentarios sobre el informe de inspección a Chazumba y Tequixtepec de 1969. In: Arqueología, INAH, n. 36, p. 240-248, 2007.

HERNÁNDEZ ASENSIO, Raúl. Las piedras suplican auxilio. Arqueólogos, huaqueros y autoridades locales en Chavín de Huantar (1870-1945). In: Historica, XXXVI.2, p. 113-138, 2012.

INAH. Programa Nacional de Museos, México D.F., 1986.

MALINOWSKI, Bronislaw; DE LA FUENTE, Julio. La economía de un sistema de mercados en México. Un ensayo de etnografía contemporánea y cambio social en un valle mexicano. In: Acta Antropológica, Época 2, v. I, n. 2, México: ENAH, 1957.

MCCARTHY, Conal. Exhibiting Mãori: A History of Colonial Cultures of Display. Wellington: Te Papa Press, 2007.

MORALES CANO, Lucero. El discurso de la teoría del desarrollo en la protección del patrimonio cultural y natural: el caso del sitio arqueológico de Chinkultic en Chiapas. In: Mesoamérica, n. 37, p. 51-71, 1999.

MORALES MORENO, Luis Gerardo. Los espejos transfigurados de Oaxaca. In: Boletín Archivo General de la Nación, n. 3, México: AGN, 1995.

OLVERA TAPIA, Leticia. Integrantes del Proyecto Arqueológico encontraron en Oaxaca un entierro. Gaceta UNAM, México, n. 3, 252, 11 feb. 1999, p. 19.

PADDOCK, John. Reflexiones en torno a la Tumba 7 de Monte Albán, cincuenta años después de su descubrimiento. In: Cuadernos de arquitectura mesoamericana, n. 7, México: UNAM, abr. 1986.

THOMPSON, Eric. Frans Blom, 1893-1963. Estudios de Cultura Maya: México, 1963. Vol. III.

VALENZUELA, Juan. Las exploraciones efectuadas en los Tuxtlas, Veracruz. In: Anales del Museo Nacional de Arqueología, Historia y Etnografia, v. 3, 1945.

VÁZQUEZ LEÓN, Luis. El Leviatán arqueológico. Antropología de una tradición científica en México. México: CIESAS, 2003.

VILLORO, Luis. Los grandes momentos del indigenismo en México. México: COLMEX/FCE, 1987.

\section{Fuentes}

BERNAL, Ignacio. Informe de la Segunda Temporada de exploraciones arqueológicas en Coixtlahuaca, 674.1, Tomo LXXXVI,
Oaxaca, 1927-1950, v. III, México: Archivo Técnico de la Coordinación Nacional de Arqueología-INAH, diciembre de 1947.

BLOM, Frans. El lienzo de Analco, Tomo LXXXIV, Estado de Oaxaca 1917-1950, Archivo Técnico de la Dirección de Monumentos Prehispánicos - INAH, 19 may. 1945.

CASO, Alfonso. Informe de las exploraciones realizadas en la población de Huamelulpan, Oaxaca, Ex-distrito de Tlaxiaco, julio 1961, 1 y 2 temporadas, 19.58, México: Archivo Técnico del Consejo de Arqueología del INAH, 16 jul. 1961.

DE LA FUENTE, Julio. Reporte de los sitios arqueológicos de los distritos de Villa Alta, Choapam, Ixtlán y Tlacolula, Oaxaca, 681.2, Tomo LXXXVII, 1917-1947, v. IV, México: Archivo Técnico de la Coordinación Nacional de Arqueología - INAH, 15 mar. 1942.

GAMIO, Lorenzo. Informe de las exploraciones en las zonas Arqueológicas de San Francisco Caxonos y Zoogocho, 683.4, Tomo LXXXVII, 1917-1947, v. IV, México: Archivo Técnico de la Coordinación Nacional de Arqueología - INAH, 4 jun. 1945.

Informe relacionado con la exploración de una tumba en el pueblo de Suchilquitongo, Oaxaca, 687.8, Tomo LXXXVII, 1917-1947, v. IV, México: Archivo Técnico de la Coordinación Nacional de Arqueología - INAH, 30 may. 1946.

. Informe relacionado con la exploración de una tumba en el pueblo de Teotitlán del Valle, Oaxaca, 619.12, Tomo LXXXVII, 1917-1947, v. IV, México: Archivo Técnico del Consejo Nacional de Arqueología - INAH, 15 nov. 1947.

Informe relacionado con visita efectuada a la zona arqueológica de Chazumba y recorrido a los cerros de Lunatitlán y Tequixtepec, Huajuapam, Oax, ref. B/311.46(02)/1, México: Departamento de Monumentos Prehispánicos, 22 nov. 1969.

Ley Federal sobre Monumentos y Zonas Arqueológicas, Artísticas e Históricas, Capítulo 1, Artículo 2, del 6 mayo de 1972.

ORTIZ DÍAZ, Edith. Informe de la temporada de campo 1997 del Proyecto Arqueológico Rio Caxonos, Villa Alta de los zapotecos, Sierra Juárez, Oaxaca, 19-116, México: Archivo Técnico del Consejo Nacional de Arqueología - INAH, febrero 1998.

ROBLES, Ramón. Las tumbas aborígenes y sus códices de piedra en la zona arqueológica de Tecomavaca. Oaxaca, Tomo LXXXVII, 1917-1947, v. IV, México: Archivo Técnico de la Coordinación Nacional de Arqueología - INAH, 1932.

VALENZUELA, Juan y DEL PEÓN, Lorenzo. Informe preliminar del resultado de visitas y exploraciones en los Estados de Oaxaca y Veracruz, 636.6, Tomo LXXXIV, Estado de Oaxaca, 1917-1949, v. II, México: Archivo Técnico de la Coordinación Nacional de Arqueología - INAH, marzo de 1949.

VARGAS, Jesús. Informe de inspección de las zonas arqueológicas del Estado de Oaxaca, 659.2, Tomo LXXIV, 1917-1947, v. II. México: Archivo Técnico de la Coordinación Nacional de Arqueología - INAH, diciembre de 1917.

Recebido: 01 de junio de 2016 Aprovado: 13 de agosto de 2016

\section{Autor/Author:}

MANUEL BURÓN DÍAZ manuel.buron@,cchs.csic.es

- Licenciado en Historia por la Universidad Complutense de Madrid (UCM), maestría y doctorado por el Instituto Universitario Investigación Ortega y Gasset (IUIOG-UCM), becario doctoral en el Grupo de Estudios Americanos del Instituto de Historia del Consejo Superior de Investigaciones Científicas (CSIC) de Madrid.

Licenciado em História pela Universidad Complutense de Madrid (UCM), mestre e doutor pelo Instituto Universitario Investigación Ortega y Gasset (IUIOG-UCM), bolsista de doutorado no Grupo de Estudos Americanos do Instituto de História do Conselho Superior de Investigações Científicas (CSIC) de Madrid.

Licenced in History by the Universidad Complutense de Madrid (UCM), Masters' degree and PhD from the Instituto Universitario Investigación Ortega y Gasset (IUIOG-UCM), doctoral scholarship in the Grupo de Estudios Americanos del Instituto de Historia del Consejo Superior de Investigaciones Científicas (CSIC) in Madrid. 